\title{
Temporal analysis of vegetation cover variation by fire action in Lábrea (AM)
}

\author{
Luís Antônio de Araújo Pinto ${ }^{1}$, Francisco Alves da Silva ${ }^{l}$
}

${ }^{1}$ Universidade do Estado do Amazonas (UEA), Mabaus, Brasil
* e-mail: $\underline{\text { lpinto@uea.edu.br }}$

\begin{abstract}
The present work aimed to analyze and quantify the areas of fire occurrence and the consequences of its action on vegetation, in the territory of Lábrea, southern region of the Amazonas state. Operational Land Imager (OLI) sensor scenes were used aboard the Landsat 8 satellite, from August and September of 2014 and 2015. These scenes were treated using remote sensing techniques, divided into two stages: (1) pre -processing (radiometric calibration, atmospheric correction, reflectance conversion and noise removal); (2) post-processing (vegetation index generation: Normalized Difference Vegetation Index - NDVI, Normalized Burn Index - NBR, image composition, interpretation, mapping, quantification and spectral behavior of vegetation). Heat source data from the Instituto Nacional de Pesquisas Espaciais (INPE) burn monitoring program were also used. The results demonstrated the high increase of hot spots in 2015, compared to 2014. The location with the highest concentration of hot spots was in the Assentamento Monte project. The use of NDVI and NBR vegetation indices showed the potential in the identification and mapping of burned areas. Comparison of hot spots with areas of effective burn demonstrated the inaccuracy of the location of the burn monitoring sensors. The total estimated burned areas in two different areas of the Lábrea municipality (AM) were 1,174.37 ha and 12,761.26 ha in August and September 2014, respectively, and 22,403.86 ha and 23,320.71 ha in August and September 2015, respectively. Through the spectral behavior of the vegetation it was noticed that the alteration of the surface reflectance after a burn, reflecting larger amount of energy in the red and blue bands. The results show that the largest amount of heat spots and burnt areas are in settlement project areas, and that the NBR vegetation index has the greatest potential to distinguish burnt areas from other vegetation types. The spectral response of the surface changes with burning events in which the red band showed higher sensitivity.
\end{abstract}

Keywords: remote sensing, vegetation index, burning, spotlights heat 